\title{
Tuberculosis Contact
}

National Cancer Institute

\section{Source}

National Cancer Institute. Tuberculosis Contact. NCI Thesaurus. Code C102573.

Any exposure to a suspected or confirmed tuberculosis causing agent. 